\title{
Potential secondary metabolite biosynthetic gene clusters and antibacterial activity of novel taxa Gandjariella
}

\author{
FITRIA NINGSIH ${ }^{1,2}$, DHIAN CHITRA AYU FITRIA SARI ${ }^{1,2}$, SHUHEI YABE ${ }^{3,4}$, AKIRA YOKOTA ${ }^{3,4}$, \\ WELLYZAR SJAMSURIDZAL ${ }^{1,2, \varphi}$ \\ ${ }^{1}$ Department of Biology, Faculty of Mathematics and Natural Sciences, Universitas Indonesia. J1. Prof. DR. Sudjono D. Pusponegoro, Kampus UI Depok, \\ Depok 16424, West Java, Indonesia. Tel.: +62-21-7270163, Fax.: +62-21-78849010, ^email: sjwelly@ sci.ui.ac.id \\ ${ }^{2}$ Center of Excellence for Indigenous Biological Resources-Genome Studies, Faculty of Mathematics and Natural Sciences, Universitas Indonesia \\ Jl. Prof. DR. Sudjono D. Pusponegoro, Kampus UI Depok, Depok 16424, West Java, Indonesia \\ ${ }^{3}$ Department of Microbial Resources, Graduate School of Agricultural Sciences, Tohoku University. 468-1 Aoba, Aramaki, Aoba-ku, Sendai, Miyagi \\ 980-0845, Japan \\ ${ }^{4}$ Hazaka Plant Research Center, Kennan Eisei Kogyo Co., Ltd. 44 Aza-Inariyama, Oaza-Ashitate, Murata-cho, Shibata-gun, Miyagi 989-1311, Japan
}

Manuscript received: 21 September 2020. Revision accepted: 20 November 2020.

\begin{abstract}
Ningsih F, Sari DCAF, Yabe S, Yokota A, Sjamsuridzal W. 2020. Potential secondary metabolite biosynthetic gene clusters and antibacterial activity of novel taxa Gandjariella. Biodiversitas 21: 5674-5684. Microbial resistance to available antibiotics has gained increasing attention in recent years and led to the urgent search for active secondary metabolites from novel microbial taxa. This study aimed to assess putative secondary metabolite biosynthetic gene clusters (BGCs) in the genome of a novel thermophilic Actinobacteria type strain Gandjariella thermophila SL3-2-4 ${ }^{\mathrm{T}}$ and screen for its antibacterial activity. Four other related novel candidate Actinobacteria strains, isolated from forest soil in the Cisolok geothermal area (West Java, Indonesia), were also screened for antibacterial activity in various media solidified with gellan gum. The genome of the SL3-2-4 $4^{\mathrm{T}}$ strain contained 21 antiSMASH-identified secondary metabolite regions harboring BGCs. These BGCs were for polyketide synthase, non-ribosomal peptide synthase, and ribosomally synthesized and post-translationally modified peptide family clusters. Three BGC regions displayed 50-100\% similarity with known secondary metabolites. Thirteen and five regions displayed low (4-35\%) and no similarity with known BGCs for secondary metabolites, respectively. Strains SL3-2-4 ${ }^{\mathrm{T}}$ and SL3-2-7 on MM 2 medium solidified with gellan gum at $45^{\circ} \mathrm{C}$ for 14 days demonstrated inhibitory activity against all Gram-positive, but not Gramnegative bacteria. Strain SL3-2-10 on ISP 3 gellan gum medium incubated for seven days only active against K. rhizophila NBRC 12078. Strains SL3-2-6 and SL3-2-9 did not exhibit any antibacterial activity against the tested bacterial strains on the three tested media. The results indicated that novel taxa have the potential for the discovery of active secondary metabolites.
\end{abstract}

Keywords: novel Actinobacteria taxa, secondary metabolites, biosynthetic gene clusters, antibacterial activity

\section{INTRODUCTION}

New antimicrobial agents with novel chemical structures are urgently needed to fight the increasing number of pathogenic microorganism strains developing resistance to available antibiotics. Natural products remain the most promising source of novel antibiotics (Tiwari and Gupta 2012). Many are derived from the filamentous Actinobacteria (traditionally called actinomycetes). Unfortunately, the discovery rate of novel antibiotics from actinomycetes has declined in recent decades due to reduced screening efforts rather than the exhaustion of compounds (Baltz 2008). This situation has encouraged researchers to explore new microbial resources for medical and industrial purposes (Bérdy 2012; Kurtböke 2012).

Members of the class Actinobacteria, especially the genus Streptomyces, have received greater attention since their discovery and are prolific producers of natural bioactive compounds. They also have an extensive secondary metabolism, producing approximately two-thirds of all naturally derived antibiotics in current clinical use and many antifungal, antibacterial, anti-parasitic, and antitumor compounds (Bérdy 2012; Solecka et al. 2012).
This extensive secondary metabolism has led to the discovery of more than 120 antibiotics, enzymes, enzyme inhibitors, and many other useful products from actinobacterial sources (Tiwari and Gupta 2012; Hamedi and Wink 2017). Therefore, actinomycetes are significant producers of medically and industrially relevant secondary metabolites (Solecka et al. 2012; Tiwari and Gupta 2012).

Currently, genomics approaches are widely used to facilitate the discovery of novel compounds by detection of putative biosynthetic gene clusters (BGCs) within bacterial genome sequences (Adamek et al. 2018). The exploitation of genome sequences to screen regions encoding biosynthetic pathways for secondary metabolite production began with the publication of the complete genome sequences of model organisms Streptomyces avermitilis ATCC 31267 (Ōmura et al. 2001) and S. coelicolor A3(2) (Bentley et al. 2002). They revealed promising BGCs that had not yet been discovered. Genome mining was developed based on these genome sequencing projects, leading to the discovery of novel compounds in many actinobacterial strains (Kersten et al. 2013; Aigle et al. 2014; Chen et al. 2016). The approach was able to identify cryptic BGCs in bacterial genomes, potentially encoding 
products with novel chemical structures, which are sometimes not expressed under conventional laboratory conditions (Rutledge and Challis 2015; Baltz 2017).

Natural products can be divided into classes according to their molecular assembly machines, most assembled in clusters, and consist of biosynthetic genes (BGCs). BGCs produce bioactive chemical compounds. Bioactive compounds can be in the form of polyketide synthases (PKSs), non-ribosomal peptide synthetases (NRPSs), ribosomally synthesized and post-translationally modified peptides (RiPPs), saccharides, terpenoids, and hybrid structures (Adamek et al. 2018; Eustáquio and Ziemert 2018). Rapid advances in genomic analysis and bioinformatics tools for identifying putative BGCs within actinobacterial strain genomes have led to the elucidation of biosynthetic pathways of previously unknown or unexplored bioactive compounds (Niu 2018). One of the most innovative and widely used tools for detecting secondary metabolite BGCs is Antibiotics and Secondary Metabolite Analysis Shell (antiSMASH). Initially released in 2011 , the updated version 4 of antiSMASH will further accelerate genome mining for novel bioactive compounds (Blin et al. 2017), including prediction of gene cluster boundaries and improved substrate specificity.

Intensive efforts have been carried out to isolate and screen rare and novel taxa of thermophilic Actinobacteria. It is done to discover new secondary metabolites from extreme temperature environments. Rare Actinobacteria are usually non-streptomycete strains with a low isolation frequency compared to streptomycete strains isolated using common methods (Tiwari and Gupta 2012). Several studies on thermophilic Actinobacteria producing bioactive compounds have been conducted previously. A study by Hu et al. (2007) showed that Streptomyces refuineus subsp. thermotolerans produces anthramycin with antitumor and antimicrobial activities. Marinactinospora thermotolerans SCSIO 00652 produces $\beta$-carboline and indolactam alkaloids with antimalarial activity (Huang et al. 2011). Microbispora aerata strain IMBAS-11A produces diketopiperazine, a neuroprotective agent (Ivanova et al. 2013). Many natural extreme environments remain either unexplored or under-explored. It could be potential resource for novel rare Actinobacteria, increasing the possibility of finding potentially novel secondary metabolites (Bérdy 2012; Tiwari and Gupta 2012).

In the previous study, a new species of thermophilic bacteria, Paenibacillus cisolokensis, was successfully isolated from litter in the Cisolok geyser, West Java, Indonesia (Yokota et al. 2016). Sjamsuridzal et al. (2017, data not shown) obtained two thermophilic Actinobacteria isolates in litter samples from the Cisolok geyser. They were identified as Actinomadura keratinilytica, which produced various extracellular enzymes, including amylase, cellulase, and xylanase, at $50{ }^{\circ} \mathrm{C}$. These isolates also demonstrated antibacterial activity towards Grampositive bacteria Kocuria rhizophila NBRC 12078 (Yokota et al. 2017, unpublished data). Ningsih et al. (2019) have been successfully isolated a novel genus and species of thermophilic Actinobacteria belonging to the family Pseudonocardiaceae known as Gandjariella thermophila
SL3-2-4 ${ }^{\mathrm{T}}$, along with five other related candidate novel strains (SL3-2-5, SL3-2-6, SL3-2-7, SL3-2-9, and SL3-2$10)$, from forest soil in the Cisolok geothermal area. These previous studies indicated the high possibility of finding novel thermophilic bacterial taxa as potential secondary metabolite producers from litter and soil samples in the Cisolok geothermal area. However, genome mining for putative secondary metabolite BGCs of strain SL3-2-4 ${ }^{\mathrm{T}}$, and its antimicrobial activity along with other related strains have not yet been described.

In silico analysis of genome sequences from novel taxa is useful to predict BGCs of potentially novel secondary metabolites. Additional information concerning the antimicrobial activity of novel taxa further confirms or refutes their potency as antibiotic producers. This study aimed to identify putative secondary metabolite BGCs from the genome of novel thermophilic Actinobacteria type strain $G$. thermophila SL3-2-4 ${ }^{\mathrm{T}}$. This study also screens antibacterial activity of the type strain along with four other related novel candidate strains.

\section{MATERIALS AND METHODS}

\section{Microorganisms}

Five novel rare thermophilic Actinobacteria strains were used in this study, namely $G$. thermophila SL3-2-4 ${ }^{\mathrm{T}}$, SL3-2-6, SL3-2-7, SL3-2-9, and SL3-2-10. They were isolated from forest soil under bamboo trees $\left(6^{\circ} 56^{\prime} 00.0^{\prime \prime} \mathrm{S}\right.$ $106^{\circ} 27^{\prime} 12.8^{\prime \prime} \mathrm{E}$ ) in the geothermal area of Cisolok (West Java, Indonesia). The type strain G. thermophila SL3-2-4 was a novel genus and species from the family Pseudonocardiaceae. The other four strains were closely related to the type strain with $99.7-100 \%$ similarity based on NCBI BLAST results (Ningsih et al. 2019). All strains were grown on International Streptomyces Project (ISP) 3 medium (Shirling and Gottlieb, 1966) solidified with gellan gum at $45{ }^{\circ} \mathrm{C}$ for 7-14 days, and maintained at room temperature as stock cultures. Long-term preservation was conducted using agar blocks in 20\% (v/v) glycerol stock solutions at $-80{ }^{\circ} \mathrm{C}$ (freezing method) and lyophilized cells (liquid-drying method) (Ningsih et al. 2019). All strains were deposited at the Universitas Indonesia Culture Collection (UICC; Universitas Indonesia, Depok, Indonesia). The test strains used for antibacterial assays included Gram-positive Bacillus subtilis NBRC 13719, Staphylococcus aureus NBRC 100910, and Kocuria rhizophila NBRC 12078, and Gram-negative Escherichia coli NBRC 3301 from NITE Biological Resource Center (NBRC) Culture Collection (Chiba, Japan), cultivated and maintained on Mueller-Hinton agar (Difco Laboratories, Detroit, MI, USA) medium.

\section{Genomic DNA extraction and whole-genome sequencing of strain SL3-2-4}

The extraction of genomic DNA for whole-genome sequencing was conducted as described by Yabe et al. (2010) and Zheng et al. (2019). Genomic DNA of the type strain G. thermophila SL3-2-4 ${ }^{\mathrm{T}}$ was prepared using a modification of the Gentra Puregene Yeast/Bact. Kit B 
protocol provided by the manufacturer (Qiagen, Hilden, Germany). Bacterial cells were collected from culture broth by centrifugation $\left(14,000 \mathrm{rpm}, 4{ }^{\circ} \mathrm{C}, 10 \mathrm{~min}\right)$. The pellet was mixed with $600 \mu \mathrm{L}$ cell suspension buffer (Qiagen), $0.5 \mathrm{mg} / \mathrm{mL}$ achromopeptidase (Wako Pure Chemical Corp., Osaka, Japan), and $0.75 \mathrm{mg} / \mathrm{mL}$ lysozyme (MP Biomedicals, LLC, Illkirch, France), followed by incubation at $37^{\circ} \mathrm{C}$ for 45 min for cell lysis. RNase A solution ( $3 \mu \mathrm{L}$, Qiagen) was added and incubated at $37{ }^{\circ} \mathrm{C}$ for one hour. Proteinase $\mathrm{K}$ (10 $\mu \mathrm{L}(20 \mathrm{mg} / \mathrm{mL})$ (Nacalai Tesque Inc., Kyoto, Japan) was added and incubated at $55^{\circ} \mathrm{C}$ for one hour, followed by gentle shaking overnight at $37^{\circ} \mathrm{C}$. Finally, $100 \mu \mathrm{L}$ DNA hydration solution (Qiagen) was added to dissolve the dried DNA pellet, which could be used for genome sequencing analysis or stored at $-20^{\circ} \mathrm{C}$ for further use.

Genome sequences were obtained using the Illumina platform (Macrogen, Kyoto, Japan). De novo assembly was used to analyze the reads using SPAdes (http: //cab.spbu.ru/software/spades/; Bankevich et al. 2012). The draft genome sequence was then submitted to the DDBJ Fast Annotation and Submission Tool server (https: //dfast.nig.ac.jp) for annotation (Tanizawa et al. 2018). The genome plot of strain SL3-2-4 ${ }^{\mathrm{T}}$ was then generated using CGView Server (http: //stothard.afns.ualberta.ca/ cgview_server/index.html; Grant and Stothard 2008). The antiSMASH tool was used to analyze secondary metabolite gene clusters within the genome (https: //antismash.secondarymetabolites.org; Blin et al. 2017).

\section{Screening for antibacterial activity}

Three different media, including ISP 3 (20 g oatmeal, $1000 \mathrm{~mL}$ distilled water, $\mathrm{pH}$ 7.3; Shirling and Gottlieb, 1966), minimal medium 1 (MM 1) (0.5 g L-asparagine, 0.5 $\mathrm{g} \mathrm{K}_{2} \mathrm{HPO}_{4}, 0.2 \mathrm{~g} \mathrm{MgSO}_{4} .7 \mathrm{H}_{2} \mathrm{O}, 0.01 \mathrm{~g} \mathrm{FeSO}_{4} .7 \mathrm{H}_{2} \mathrm{O}, 10 \mathrm{~g}$ glucose, $1000 \mathrm{~mL}$ distilled water, $\mathrm{pH}$ 7.0-7.2; Hopwood, 1967), and minimal medium 2 (MM 2) $\left(0.5 \mathrm{~g}\left(\mathrm{NH}_{4}\right)_{2} \mathrm{SO}_{4}\right.$, $0.5 \mathrm{~g} \mathrm{~K}_{2} \mathrm{HPO}_{4}, 0.2 \mathrm{~g} \mathrm{MgSO}_{4} .7 \mathrm{H}_{2} \mathrm{O}, 0.01 \mathrm{~g} \mathrm{FeSO}_{4} .7 \mathrm{H}_{2} \mathrm{O}, 10$ $\mathrm{g}$ glucose, $1000 \mathrm{~mL}$ distilled water, $\mathrm{pH}$ 7.0-7.2; Kieser et al. 2000), were solidified with $2 \%$ gellan gum (added with $0.2 \% \mathrm{MgCl}_{2}$ ). They are used as growth media for the Actinobacteria strains. All Actinobacteria strains were cultivated at $45{ }^{\circ} \mathrm{C}$ for 7 and 14 days of incubation. Antibacterial activity was tested against Gram-positive $S$. aureus, B. subtilis, and K. rhizophila, and Gram-negative $E$. coli. The tested bacterial strains were grown on nutrient broth (NB) medium overnight at $30{ }^{\circ} \mathrm{C}$ in a shaking incubator, one day before the 7th and 14th days of actinobacterial strains incubation. Antibacterial activity was assessed using the agar plug diffusion method (Balouiri et al. 2016). Agar plugs of 7 and 14-day Actinobacteria cultures were placed on the surface of Mueller-Hinton agar containing the test strains. The inhibition zone was observed after overnight incubation at $30^{\circ} \mathrm{C}$.

\section{RESULTS AND DISCUSSION}

\section{Morphology of actinobacterial strains in various media solidified with gellan gum}

The five actinobacterial strains were observed for colony growth (substrate mycelium formation), soluble pigment production, and spore formation after incubation for 14 days at $45{ }^{\circ} \mathrm{C}$ (Table 1, Figure 1). All strains exhibited good growth and abundant formation of spore and substrate mycelium on ISP 3 gellan gum medium. Soluble pigment production was also observed on ISP 3 gellan gum medium. Strains SL3-2-4 ${ }^{\mathrm{T}}$, SL3-2-7, and SL32-10 produced dark-orange, wine-red, and light-orange pigment, respectively, but no pigment was observed for strains SL3-2-6 and SL3-2-9. Growth or substrate mycelium formation on MM 1 and MM 2 gellan gum media was abundant in all strains. However, spore formation and soluble pigment production were not observed in any strain on MM 1 and 2 gellan gum media.

Mycelial Actinobacteria, like members of the Streptomyces genus, exhibit a wide variety of morphologies, including the presence or absence of aerial mycelium, mycelium color, production of diffusible melanoid pigments, and the structure and appearance of their spores (Barka et al. 2016). These morphologies are important factors in genera differentiation but do not provide adequate information for classification. The formation of both substrate and aerial mycelium is mainly affected by nutrient availability and other favorable conditions (e.g., $\mathrm{pH}$, temperature, $\mathrm{NaCl}$ tolerance) (Mohammadipanah and Dehhaghi 2017). Actinobacteria spores will germinate and tend to form substrate mycelia under favorable conditions with adequate nutrients. Conversely, many morphological differentiations occur when sufficient nutrients are not available to cells, such as aerial hyphae (Hamedi et al. 2017). This morphological differentiation is associated with antibiotic production, exemplified by Saccharopolyspora erythraea, Streptomyces avermitilis, and S. coelicolor produced erythromycin, avermectin, and actinorhodin, respectively (Barka et al. 2016).

Standard ISP media are used for the cultivation and characterization of Streptomyces species (Shirling and Gottlieb, 1966). These media are used to describe strain characteristics such as the color of the colony, spore, and aerial and substrate mycelium, as well as diffusible pigment characteristics (Mohammadipanah and Dehhaghi 2017). In this study, the representative ISP 3 medium solidified with gellan gum was used for cultivation. This medium showed abundant spore formation in 11 of 12 rare thermophilic actinobacterial isolates (Sari et al. 2020). Meanwhile, minimal medium (MM) was previously used as a sporulation medium for maintaining stock cultures and plating S. coelicolor spore suspensions (Hopwood and Sermonti 1963; Hopwood 1967). Gellan gum was employed as a solidifying agent in the cultivation media due to its high thermal stability, making it suitable as a growth medium for thermophiles (Das et al. 2015). Previously, gellan gum successfully improved the growth of slow-growing actinobacterium Frankia sp. strain $\mathrm{Ccl} 3$ in solid media by increasing colony development and spore germination efficiency in other Frankia strains (Bassi and Benson 2007).

Actinobacteria produce several pigments that affect colonies, medium, and aerial mycelium based on their water solubility. Production of pigments depends on medium substances, culture conditions, and age of the strain. Members of Actinobacteria produce a dark pigment, 
melanin, which is considered valuable for taxonomic relatedness. Melanins are polymers with diverse structures produced by a broad range of organisms (Barka et al. 2016; Mohammadipanah and Dehhaghi 2017). Melanins have important roles, including contributing to the structural rigidity of cell walls to protect against stress caused by high temperature, heavy metals, and exposure to solar UV radiation. Previously, Streptomyces glaucescens strain NEAE-H, isolated from a soil sample in Al-Taif, Saudi Arabia, demonstrated anticancer and antioxidant activities from its extracellular melanin pigment (El-Naggar and ElEwasy 2017).

\section{Genome features and putative secondary metabolite} BGCs of the type strain Gandjariella thermophila SL3-2-4 ${ }^{\text {T }}$

The genome of the type strain G. thermophila SL3-2-4 comprised $6.12 \mathrm{Mb}$ with 5,740 protein-coding genes, 131 contigs, and $71.6 \mathrm{~mol} \%$ DNA GC content (Ningsih et al. 2019). The circular genome plot generated by the CGView Server is shown in Figure 2. The CGView Server generated genome maps with contigs 409,311 bp in length, displayed open reading frames (ORFs), start and stop codons, guanine, and cytosine (GC) composition, and GC skews. They are useful for the identification of conserved or diverged genome fragments. Comparisons between genome maps within a family can be used for sequence identification. Visualization of the known genome region enfolded by newly acquired genome sequences can also be observed in the generated maps (Grant and Stothard 2008).

The genome sequence of the family members of Pseudonocardiaceae that are available to the public includes the genera Amycolatopsis, Saccharomonospora, Saccharopolyspora, Saccharothrix, Pseudonocardia, and Thermobispora. Their features and secondary metabolite clusters have been compared and analyzed. Amycolatopsis mediterranei $\mathrm{U} 32$ has the largest genome with $10.2 \mathrm{Mb}$ (9,228 CDS), while Thermobispora bispora DSM 43833 has the smallest genome with 4.1 Mb (3,596 CDS) (Strobel et al. 2012), compared to G. thermophila SL3-2-4 ${ }^{\mathrm{T}}$ with $6.12 \mathrm{Mb}(5,740 \mathrm{CDS})$. The highest number of secondary metabolite clusters was identified in Saccharopolyspora erythraea NRRL 2338 (8.2 Mb genome size; 7,198 CDS), Saccharothrix espanaensis DSM 44229 (9.36 Mb genome size; 8,427 CDS), and A. mediterranei U32 with 30, 26, and 25 clusters, respectively. Conversely, the lowest number of secondary metabolite clusters was discovered in Pseudonocardia dioxanivorans CB1190 (7.09 Mb genome size) and T. bispora DSM 43833 with only 5 clusters each (Strobel et al. 2012).

A total of 21 secondary metabolite regions harboring BGCs for PKS, NRPS, and RiPP family clusters were identified in the genome of the type strain SL3-2-4 ${ }^{\mathrm{T}}$ (Table 2 ). One region matched with known ectoine BGC from Streptomyces anulatus with $100 \%$ similarity. Ectoine is an organic low-molecular-weight compound accumulated by microorganisms as protection from stress due to heating, high osmotic pressure, freezing, desiccation, and exposure to salt. Nowadays, ectoine is utilized in various biotechnology applications, including a moisturizer in cosmetics and skincare products (Prabhu et al. 2004). Three clusters (regions 1.2, 1.3, and 2.2) were possibly encoding terpenoid biosynthetic enzymes. Cluster in region 1.2 display $53 \%$ similarity with hopene BGC from $S$. coelicolor A3(2) (Redenbach et al. 1996; Bentley et al. 2002). Clusters in region 1.3 and 2.2 showed $18 \%$ similarity with carotenoid BGC from $S$. avermitilis ATCC 31267 (Ōmura et al. 2001), and 4\% similarity with SF2575 (polyketide: type II + saccharide: hybrid/tailoring) BGC from Streptomyces sp. SF2575 (Hatsu et al. 1992; Pickens et al. 2009; Pickens et al. 2011; Li et al. 2014), respectively. Bacterial terpenes, generated by terpene cyclase, comprise large, structurally diverse, natural products with potential bioactivity and are particularly produced by actinomycetes, myxobacteria, and cyanobacteria (Rabe et al. 2013). Many terpenes demonstrate biological activities (metabolic, structural, physiological, and defensive mechanisms) and have pharmacological significance, including antioxidant, antiinflammatory, antimicrobial, and anticancer properties (Gonzales-Burgos and Gomez-Serranillos 2012).

Table 1. Morphological characteristics of strains SL3-2-4 ${ }^{\mathrm{T}}$, SL3-2-6, SL3-2-7, SL3-2-9, and SL3-2-10 at $45^{\circ} \mathrm{C}$ for 14 days of incubation

\begin{tabular}{|c|c|c|c|c|c|}
\hline Isolate code & Medium & $\begin{array}{c}\text { Substrate mycelium } \\
\text { (growth) }\end{array}$ & $\begin{array}{c}\text { Spore } \\
\text { formation }\end{array}$ & $\begin{array}{c}\text { Color of substrate } \\
\text { mycelium }\end{array}$ & Soluble pigment \\
\hline \multirow[t]{3}{*}{ SL3-2-4 ${ }^{\mathrm{T}}$} & ISP 3 gellan gum & +++ & +++ & Dark-orange & Dark-orange \\
\hline & MM 1 gellan gum & +++ & - & Ivory & - \\
\hline & MM 2 gellan gum & +++ & - & Light-orange & - \\
\hline \multirow[t]{3}{*}{ SL3-2-6 } & ISP 3 gellan gum & +++ & +++ & White & - \\
\hline & MM 1 gellan gum & +++ & - & Ivory & - \\
\hline & MM 2 gellan gum & +++ & - & Cream & - \\
\hline \multirow[t]{3}{*}{ SL3-2-7 } & ISP 3 gellan gum & +++ & +++ & Wine-red & Wine-red \\
\hline & MM 1 gellan gum & +++ & - & Cream & - \\
\hline & MM 2 gellan gum & +++ & - & Dark-orange & - \\
\hline \multirow[t]{3}{*}{ SL3-2-9 } & ISP 3 gellan gum & +++ & +++ & Deep-green & - \\
\hline & MM 1 gellan gum & +++ & - & Ivory & - \\
\hline & MM 2 gellan gum & +++ & - & Orange & - \\
\hline \multirow[t]{3}{*}{ SL3-2-10 } & ISP 3 gellan gum & +++ & +++ & Light-orange & Light-orange \\
\hline & MM 1 gellan gum & +++ & - & Light-orange & - \\
\hline & MM 2 gellan gum & +++ & - & Orange-yellow & - \\
\hline
\end{tabular}

Note: +++, abundant; ++, moderate; +, poor; -, absent 
ISP 3 gellan gum

A

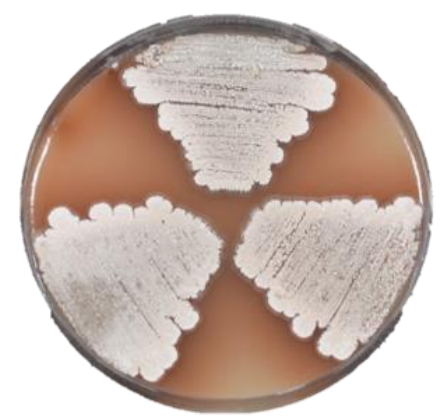

B

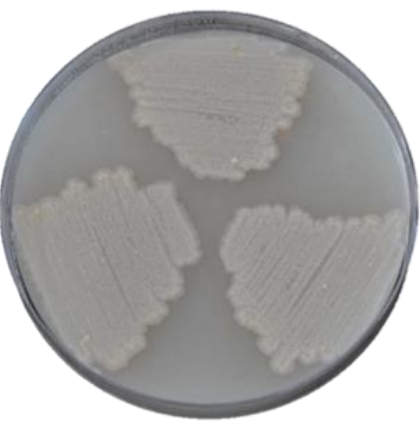

C

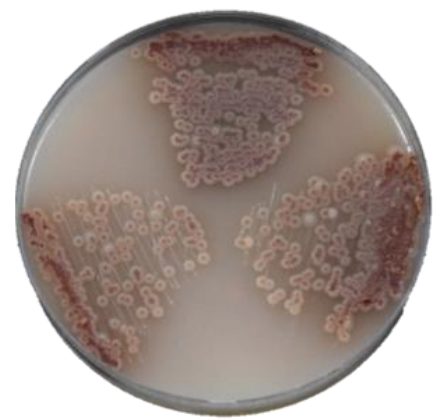

D

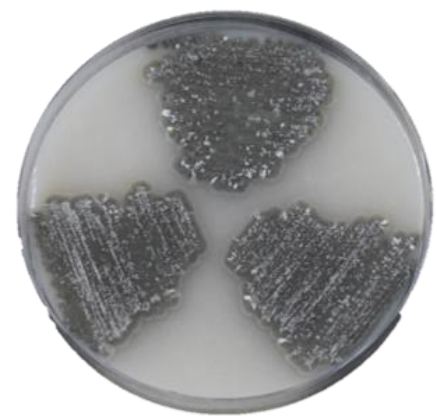

$\mathbf{E}$

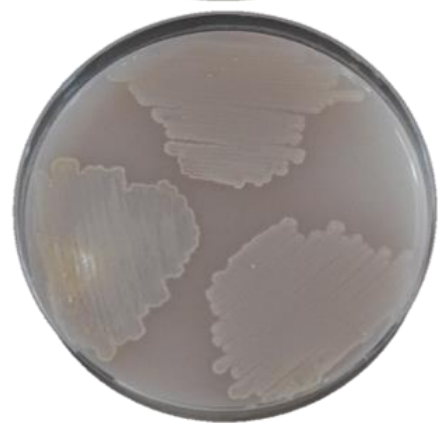

MM 1 gellan gum
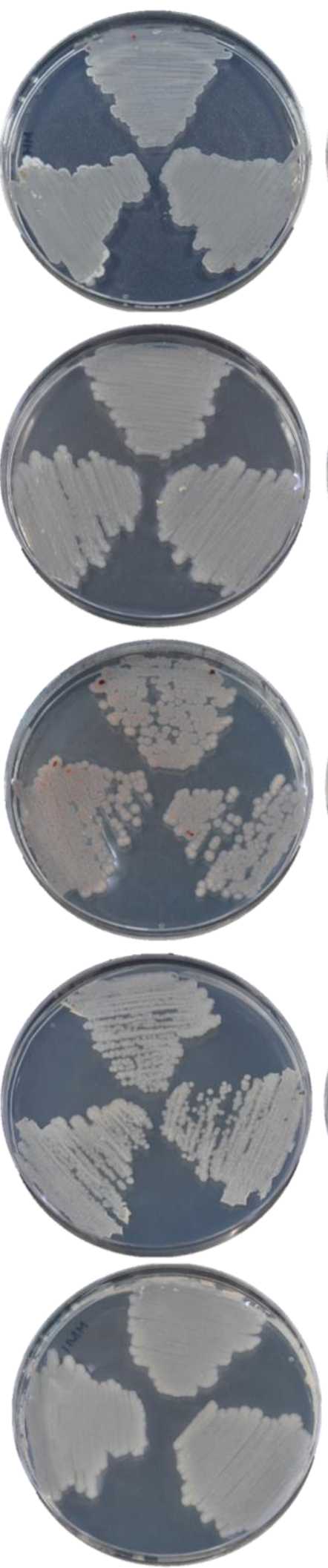

MM 2 gellan gum
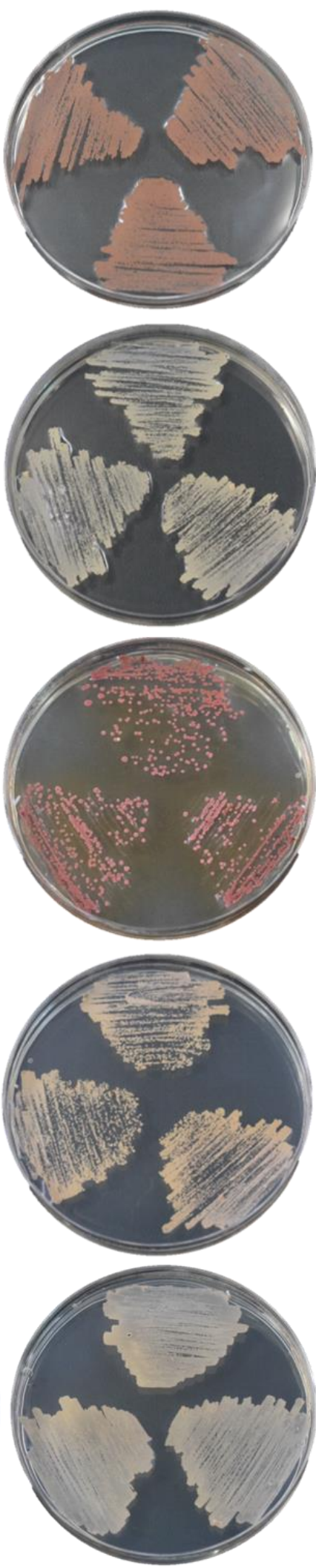

Figure 1. Morphology of strains (A) Gandjariella thermophila SL3-2-4 , (B) SL3-2-6, (C) SL3-2-7, (D) SL3-2-9, and (E) SL3-2-10, grown on ISP 3, MM 1, and MM 2 gellan gum media at $45^{\circ} \mathrm{C}$ after 14 days of incubation. 
PKSs and NRPSs are advanced molecular tools engaged in numerous bacterial natural products (Donadio et al. 2007). PKSs are modular assembly line enzymes classified into three groups, types I, II, and III, based on the construction of the biosynthetic enzymes. Four clusters were identified in the genome of the type strain SL3-2-4 ${ }^{\mathrm{T}}$ to produce type II PKS (T2PKS) displaying 52, 32, 21, and $13 \%$ similarity with known clusters including lysolipin I BGC from Streptomyces tendae Tü 4042 (Lopez et al. 2010), paramagnetoquinone 1 BGC from Actinoallomurus sp. ID145113 (Iorio et al. 2017), griseohordin A BGC from Streptomyces sp. JP95 (Li et al. 2002; Lackner et al. 2007; Yunt et al. 2009), and murayaquinone BGC from Streptomyces griseoruber Sgr29 (Gao et al. 2017), respectively. Region 17.2 was recognized as cyanobactintype BGC showing 4\% similarity with the dutomycin BGC of Streptomyces minoensis NRRL B-5482 which possessed two PKS systems, including a type II PKS and a rare highly reducing iterative type I PKS (Sun et al. 2016). Meanwhile, type III PKS displaying $28 \%$ similarity with alkyl-Odihydrogeranyl-methoxyhydroquinone BGC from Actinoplanes missouriensis 431, was identified in region 31.1 (Awakawa et al. 2011). PKS-derived natural products are synthesized by decarboxylative condensation of malonyl-CoA, involving acyltransferase (AT), thiolation (T), or acyl carrier protein (ACP), and ketosynthase (KS) (Strobel et al. 2012; Eustáquio and Ziemert 2018). The widely-known actinomycete-derived antibiotics synthesized by PKS were erythromycin from Saccharopolyspora erythraea and tetracycline from Streptomyces (Fischbach and Walsh 2006). Clusters containing PKSs in the genome of the type strain $G$. thermophila were the largest in size, ranging between 57$86 \mathrm{~kb}$.

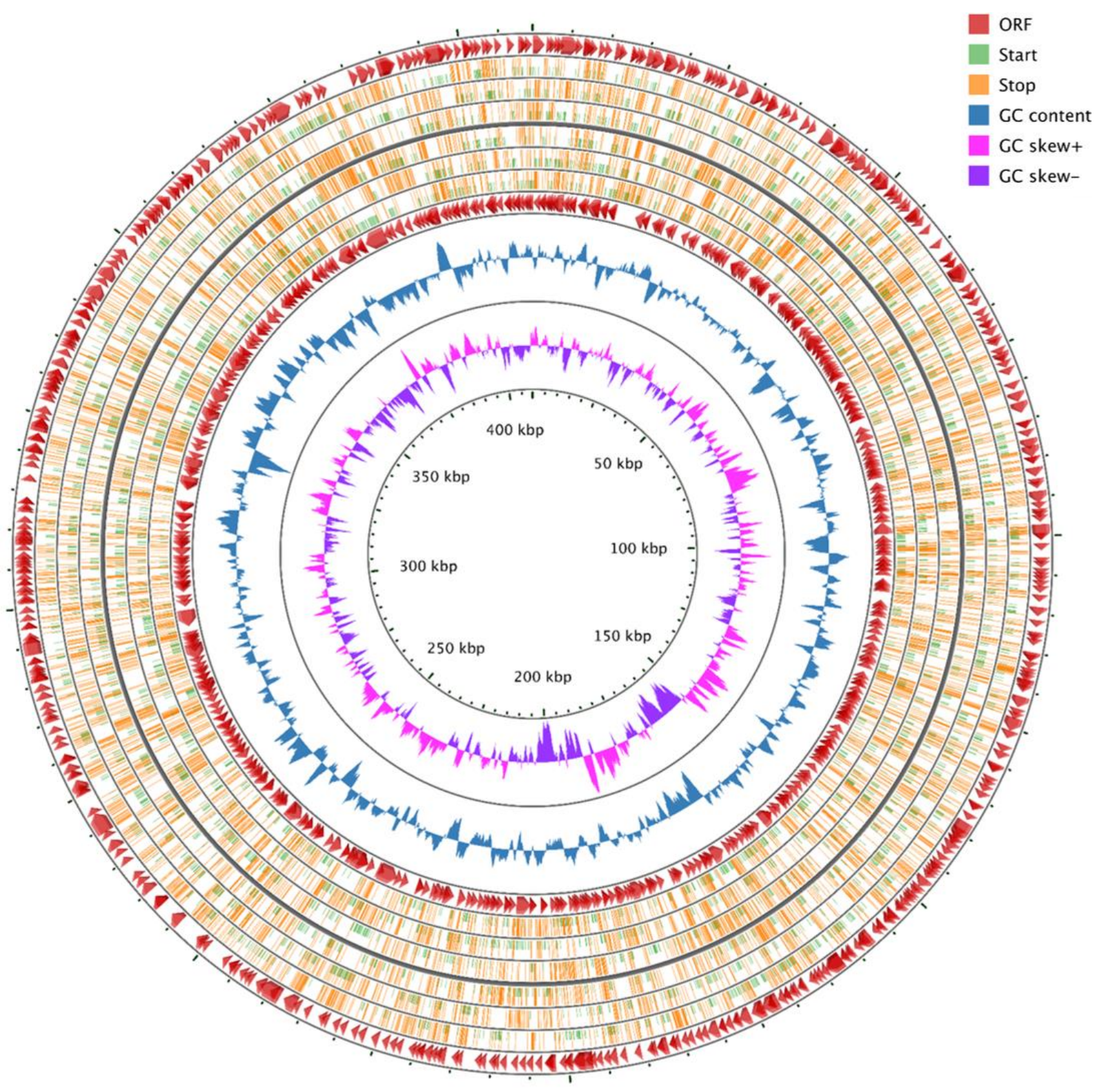

Figure 2. The genome plot of strain Gandjariella thermophila SL3-2-4 ${ }^{\mathrm{T}}$ with contigs 409,311 bp in length. The colored boxes indicate open reading frames (ORFs) in red, start codons in green, stop codons in orange, guanine and cytosine (GC) content in blue, GC skew+ in pink, and GC skew- in purple 
Table 2. Classification of putative biosynthetic gene clusters (BGCs) in strain Gandjariella thermophila SL3-2-4 ${ }^{\mathrm{T}}$ identified by antiSMASH

\begin{tabular}{|c|c|c|c|c|c|c|}
\hline Contig & Region & Position & $\begin{array}{l}\text { Types of } \\
\text { secondary } \\
\text { metabolite } \\
\text { clusters }\end{array}$ & Most similar known cluster & Similarity & Reference \\
\hline \multirow[t]{3}{*}{1} & 1.1 & $156,021-177,205$ & Indole & - & - & - \\
\hline & 1.2 & $308,109-334,468$ & Terpene & $\begin{array}{l}\text { Hopene BGC from Streptomyces coelicolor } \\
\mathrm{A} 3(2)\end{array}$ & $53 \%$ & $\begin{array}{l}\text { Redenbach et al. (1996); } \\
\text { Bentley et al. (2002) }\end{array}$ \\
\hline & 1.3 & $347,583-368,527$ & Terpene & $\begin{array}{l}\text { Carotenoid BGC from Streptomyces } \\
\text { avermitilis ATCC } 31267\end{array}$ & $18 \%$ & Omura et al. (2001) \\
\hline \multirow[t]{3}{*}{2} & 2.1 & $75,159-90,602$ & Siderophore & $\begin{array}{l}\text { Ficellomycin (NRP) BGC from } \\
\text { Streptomyces ficellus NRRL } 8067\end{array}$ & $9 \%$ & Liu et al. (2017) \\
\hline & 2.2 & $177,552-198,748$ & Terpene & $\begin{array}{l}\text { SF2575 (Polyketide: Type II + Saccharide: } \\
\text { Hybrid/tailoring) BGC from Streptomyces } \\
\text { sp. SF2575 }\end{array}$ & $4 \%$ & $\begin{array}{l}\text { Hatsu et al. (1992); } \\
\text { Pickens et al. (2009); } \\
\text { Pickens et al. (2011); Li } \\
\text { et al. (2014) }\end{array}$ \\
\hline & 2.3 & $219,430-263,533$ & NRPS-like & $\begin{array}{l}\text { A-500359 A/A-500359 B BGC from } \\
\text { Streptomyces griseus SANK60196 }\end{array}$ & $8 \%$ & Funabashi et al. (2009) \\
\hline \multirow[t]{2}{*}{4} & 4.1 & $81,243-93,324$ & Butyrolactone & - & - & - \\
\hline & 4.2 & $149,988-222,473$ & T2PKS & $\begin{array}{l}\text { Griseohordin A BGC from Streptomyces } \\
\text { sp. JP95 }\end{array}$ & $21 \%$ & $\begin{array}{l}\text { Li et al. (2002); Lackner } \\
\text { et al. (2007); Yunt et al. } \\
\text { (2009) }\end{array}$ \\
\hline 6 & 6.1 & $36,995-47,408$ & Ectoine & Ectoine BGC from Streptomyces anulatus & $100 \%$ & Prabhu et al. (2004). \\
\hline 11 & 11.1 & $34,168-120,278$ & T2PKS & $\begin{array}{l}\text { Lysolipin I BGC from Streptomyces tendae } \\
\text { Tü } 4042\end{array}$ & $52 \%$ & Lopez et al. (2010) \\
\hline 14 & 14.1 & $41,695-62,660$ & Nucleoside & $\begin{array}{l}\text { S56-p1 (NRP) BGC from Streptomyces sp. } \\
\text { SoC090715LN-17 }\end{array}$ & $5 \%$ & Matsuda et al. (2017) \\
\hline 16 & 16.1 & $85,977-108,847$ & Lanthipeptide & $\begin{array}{l}\text { Stenothricin (NRP: Cyclic depsipeptide) } \\
\text { BGC from Streptomyces filamentosus } \\
\text { NRRL } 15998\end{array}$ & $9 \%$ & Liu et al. (2014) \\
\hline \multirow[t]{2}{*}{17} & 17.1 & $8,135-80,638$ & T2PKS & $\begin{array}{l}\text { Paramagnetoquinone } 1 \text { BGC from } \\
\text { Actinoallomurus sp. ID145113 }\end{array}$ & $32 \%$ & Iorio et al. (2017) \\
\hline & 17.2 & $95,558-113,297$ & Cyanobactin & $\begin{array}{l}\text { Dutomycin (polyketide) BGC from } \\
\text { Streptomyces minoensis NRRL B-5482 }\end{array}$ & $4 \%$ & Sun et al. (2016) \\
\hline 19 & 19.1 & $22,741-47,071$ & Lanthipeptide & $\begin{array}{l}\text { Pyrrolomycin A (Polyketide) BGC from } \\
\text { Streptomyces vitaminophilus ATCC } 31673\end{array}$ & $5 \%$ & Zhang et al. (2007) \\
\hline 20 & 20.1 & $1-57,160$ & T2PKS & $\begin{array}{l}\text { Murayaquinone BGC from Streptomyces } \\
\text { griseoruber Sgr } 29\end{array}$ & $13 \%$ & Gao et al. (2017) \\
\hline 31 & 31.1 & $30,695-60,360$ & $\begin{array}{l}\text { Bacteriocin, } \\
\text { T3PKS }\end{array}$ & $\begin{array}{l}\text { Alkyl-O-dihydrogeranyl- } \\
\text { methoxyhydroquinones BGC from } \\
\text { Actinoplanes missouriensis } 431\end{array}$ & $28 \%$ & Awakawa et al. (2011) \\
\hline 42 & 42.1 & $1-37,682$ & NRPS-like & - & - & - \\
\hline 43 & 43.1 & $14,992-34,882$ & Lanthipeptide & $\begin{array}{l}\text { Goadsporin (RiPP: LAP) BGC from } \\
\text { Streptomyces sp. TP-A0584 }\end{array}$ & $12 \%$ & Onaka et al. (2005) \\
\hline 59 & 59.1 & $1-16,574$ & $\begin{array}{l}\text { NRPS-like, } \\
\text { T1PKS }\end{array}$ & - & - & - \\
\hline 62 & 62.1 & $1-9,438$ & Bacteriocin & - & - & - \\
\hline
\end{tabular}

Notes: BGC: biosynthetic gene cluster; LAP: linear azol(in)e-containing peptide; NRPS: non-ribosomal peptide synthetase cluster; NRPS-like: NRPS-like fragment; RiPP: ribosomally synthesized and post-translationally modified peptide; T1PKS: Type I polyketide synthase (PKS); T2PKS: Type II PKS; T3PKS: Type III PKS.

Three NRPS-like encoding clusters were also identified, displaying an $8 \%$ similarity with A-500359 A/A-500359 B BGC from Streptomyces griseus SANK60196 (Funabashi et al. 2009). Meanwhile, other NRPS-like (region 42.1) and NRPS-like/PKS type I hybrid (region 59.1) clusters were unknown to other publicly available clusters. NRPSs comprise multimodular enzymatic lines including adenylation (A), thiolation ( $\mathrm{T})$, and condensation (C) domains (Strobel et al. 2012). The A domains selected amino acids for building blocks then transferred to $\mathrm{T}$ (also named peptidyl carrier protein or PCP) domains, followed by condensation (C) domains, which catalyze peptide bond formation (Eustáquio and Ziemert 2018). NRPS-produced antibiotics derived from actinomycetes were vancomycin by Amycolatopsis orientalis HCCB10007 and bleomycin by Streptomyces verticillus ATCC 15003 (Fisbach and Walsh 2006).

Other regions harboring three putative lanthipeptidetype clusters displayed 12,9 , and $5 \%$ similarity with goadsporin BGC from Streptomyces sp. TP-A0584 (Onaka 
et al. 2005), stenothricin BGC from Streptomyces filamentosus NRRL 15998 (Liu et al. 2014), and pyrrolomycin A BGC from S. vitaminophilus ATCC 31673 (Zhang et al. 2007), respectively. Lanthipeptides are among the most-studied subgroup of RiPPs, renowned for compounds distinguished by sulfur-to- $\beta$-carbon thioether cross-links, named lanthionines and methyllanthionines. Lanthipeptides with strong antimicrobial activity are known as lantibiotics, such as a commercial food preservative nisin (Zhang et al. 2015). Remaining clusters consisted of siderophore-type displaying 9\% similarity with ficellomycin BGC from Streptomyces ficellus NRRL 8067 (Liu et al. 2017); and nucleoside-type with 5\% similarity with S56-p1 BGC from Streptomyces sp. SoC090715LN17 (Matsuda et al. 2017). Interestingly, the last five clusters had no similarities with other publicly known clusters and identified as indole-, butyrolactone-, NRPS-like, NRPSlike/T1PKS hybrid, and bacteriocin-types. The presence of low and no-similarity type clusters compared with published known clusters suggested the high potential of strain SL3-2-4 ${ }^{\mathrm{T}}$ to produce novel bioactive compounds.

\section{Antibacterial activity of Actinobacteria strains in different media solidified with gellan gum}

Agar plugs from the five Actinobacteria strains were tested against Gram-positive and-negative bacterial strains. The antibacterial activity of the five strains is shown in Table 3 and Figure 3. Two strains, SL3-2-4 and SL3-2-7, demonstrated positive results against all Gram-positive bacterial strains on MM 2 gellan gum medium incubated at $45{ }^{\circ} \mathrm{C}$ for 14 days. Strains SL3-2-4 ${ }^{\mathrm{T}}$ and SL3-2-10 exhibited activity against $K$. rhizophila NBRC 12078 on ISP 3 gellan gum medium incubated for 7 days. Meanwhile, SL3-2-7 showed positive activity against $S$. aureus NBRC 100910 and K. rhizophila NBRC 12078 on ISP 3 gellan gum medium incubated for 14 days. Among the three media tested with strains SL3-2-4 ${ }^{\mathrm{T}}$, SL3-2-7, and
SL3-2-10, the MM 1 gellan gum medium had no inhibitory activity against the tested Gram-positive and -negative bacteria. In addition, the three strains of Actinobacteria did not show activity against $E$. coli NBRC 3301 in the three media tested. Comparatively, strains SL3-2-6 and SL3-2-9 did not display antibacterial activity against any of the tested strains in the three media at 7 and 14 days of incubation.

The discovery of novel actinomycete-derived antibiotics has declined in recent decades, leading more researchers to exploit new microbial resources for valuable microbial metabolites (Bérdy 2012; Kurtböke 2012). Several species of novel taxa of Actinobacteria have been reported to produce bioactive compounds. Micromonospora lupini sp. nov. produces antitumor anthraquinones (Igarashi et al. 2007). Verrucosispora sediminis sp. nov. produces cyclodipeptide (Dai et al. 2010), and Pseudonocardia antitumoralis sp. nov. produces antitumor agent deoxynyboquinone (Tian et al. 2013).

The 'One Strain-Many Compounds (OSMAC) approach' developed by Bode et al. (2002) induces chemical diversity by modifying cultivation parameters, i.e., composition media, temperature, $\mathrm{pH}$ value, culture flask, oxygen supply, and addition of enzyme inhibitors. The approach was based on the observation that the metabolic profile of various microorganisms changed entirely when cultivation conditions were altered. OSMAC successfully induced one microorganism, Streptomyces sp. Gö40/14, to produce up to 20 different secondary metabolites (Bode et al. 2002). The antibacterial activity results from the five Actinobacteria strains on various media at varied incubation times demonstrated that the production of their active secondary metabolites was affected by cultivation media (availability of nutrients), solidifying agents, as well as incubation time.

Table 3. Antibacterial activity of Actinobacteria strains grown on ISP 3, MM 1, and MM 2 media solidified with gellan gum at $45^{\circ} \mathrm{C}$

\begin{tabular}{|c|c|c|c|c|c|c|c|c|c|}
\hline \multirow{3}{*}{ Strain codes } & \multirow{3}{*}{$\begin{array}{l}\text { Growth } \\
\text { media }\end{array}$} & \multicolumn{8}{|c|}{ Antibacterial activity (zone inhibition in $\mathrm{mm}$ ) } \\
\hline & & \multicolumn{2}{|c|}{$\begin{array}{c}\text { B. subtilis } \\
\text { NBRC } 13719\end{array}$} & \multicolumn{2}{|c|}{$\begin{array}{c}\text { S. aureus } \\
\text { NBRC 100910 }\end{array}$} & \multicolumn{2}{|c|}{$\begin{array}{c}\text { K. rhizophila NBRC } \\
12078\end{array}$} & \multicolumn{2}{|c|}{$\begin{array}{c}\text { E. coli } \\
\text { NBRC 3301 }\end{array}$} \\
\hline & & 7 days & 14 days & 7 days & 14 days & 7 days & 14 days & 7 days & 14 days \\
\hline \multirow[t]{3}{*}{ SL3-2-4 ${ }^{\mathrm{T}}$} & 1 & - & - & - & - & 9.18 & - & - & - \\
\hline & 2 & - & - & - & - & - & - & - & - \\
\hline & 3 & - & 12.30 & - & 13.48 & - & 18.14 & - & - \\
\hline \multirow[t]{3}{*}{ SL3-2-6 } & 1 & - & - & - & - & - & - & - & - \\
\hline & 2 & - & - & - & - & - & - & - & - \\
\hline & 3 & - & - & - & - & - & - & - & - \\
\hline \multirow[t]{3}{*}{ SL3-2-7 } & 1 & - & - & - & 12.22 & - & 10.37 & - & - \\
\hline & 2 & - & - & - & - & - & - & - & - \\
\hline & 3 & - & 11.60 & - & 13.51 & - & 14.34 & - & - \\
\hline \multirow[t]{3}{*}{ SL3-2-9 } & 1 & - & - & - & - & - & - & - & - \\
\hline & 2 & - & - & - & - & - & - & - & - \\
\hline & 3 & - & - & - & - & - & - & - & - \\
\hline \multirow[t]{3}{*}{ SL3-2-10 } & 1 & - & - & - & - & 9.87 & - & - & - \\
\hline & 2 & - & - & - & - & - & - & - & - \\
\hline & 3 & - & - & - & - & - & - & - & - \\
\hline
\end{tabular}

Notes: (1): ISP 3 gellan gum; (2): MM 1 gellan gum; (3): MM 2 gellan gum; (-): no inhibition zone observed 


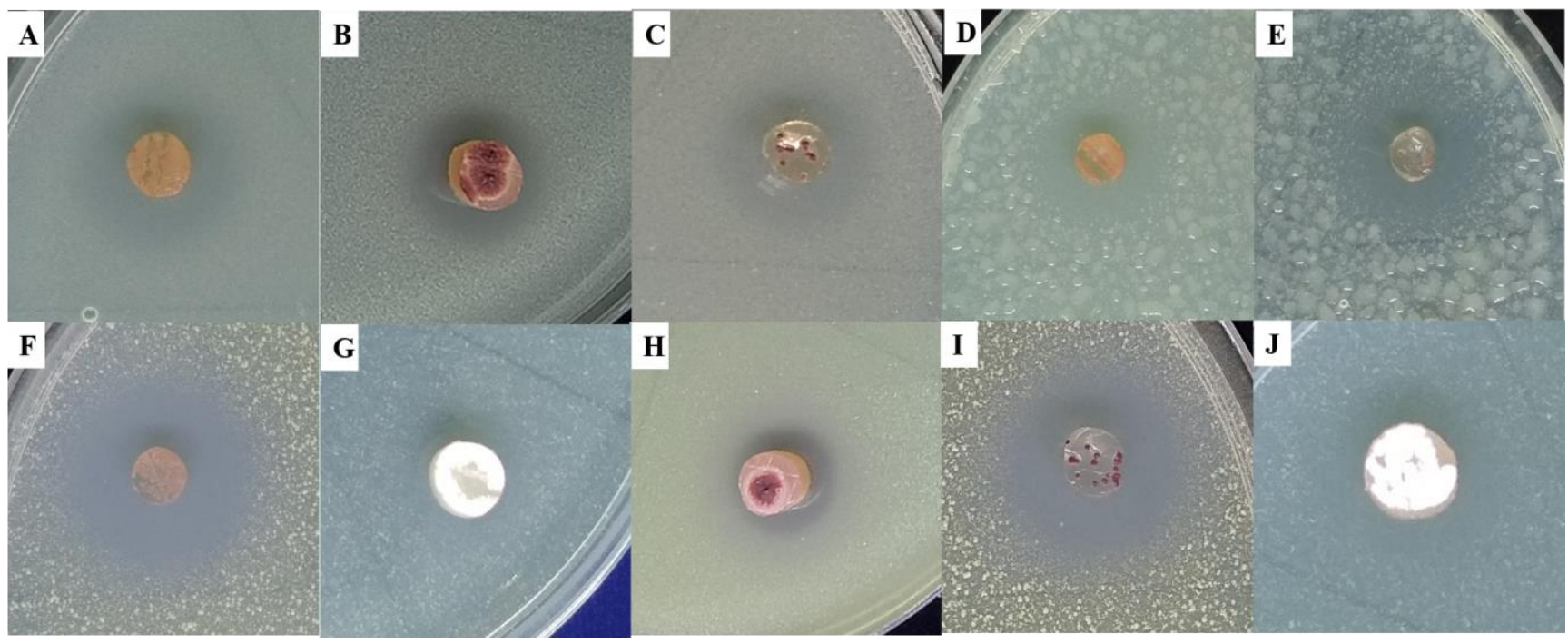

Figure 3. Antibacterial activity of Actinobacteria strains on various media solidified with gellan gum against $S$. aureus NBRC 1000910 (A) SL3-2-4 ${ }^{\mathrm{T}}$ on MM 2, (B) SL3-2-7 on ISP 3, (C) SL3-2-7 on MM 2; B. subtilis NBRC 13719 (D) SL3-2-4 ${ }^{\mathrm{T}}$ on MM 2, (E): SL3-2-7 on MM 2); and K. rhizophila NBRC 12078 (F) SL3-2-4 ${ }^{\mathrm{T}}$ on MM 2, (G) SL3-2-4 ${ }^{\mathrm{T}}$ on ISP 3, (H) SL3-2-7 on ISP 3, (I) SL3-2-7 on MM 2, (J) SL3-2-10 on ISP 3

The medium used for cultivation can influence microorganism growth and metabolism. The carbon/nitrogen $(\mathrm{C} / \mathrm{N})$ ratio, salinity, and metal ions control the level and pattern of gene expression in microorganisms leading to the production of various secondary metabolites. The utilization of a cultivation medium containing carbon and nitrogen-based components changes the $\mathrm{pH}$ of the medium due to the emergence of organic acids or the aggregation of primary ammonium. Microorganisms will then express specific sets of biosynthetic genes and synthesize various specific metabolites (Pan et al. 2019). In this study, we employed gellan gum as a solidifying agent since it was known to induce best aerial mycelium and spore formation in Actinobispora yunnanensis IFO $15681^{\mathrm{T}}$, and other rare actinomycete genera, i.e., Sporichthya, Planobispora, and Planomonospora. Gellan gum was also previously used as a solidifying agent for isolation media from which novel bioactive metabolite-producing strains were successfully obtained (Suzuki 2001).

New and improved antibacterial agents are urgently needed to treat infections caused by increasingly resistant strains of pathogenic microorganisms (Tiwari and Gupta 2012). This study suggested that G. thermophila SL3-2-4 ${ }^{\mathrm{T}}$ and other closely related novel candidate strains showed promising results for producing active secondary metabolites. Analysis of antiSMASH-identified secondary metabolite BGCs in the type strain SL3-2-4 ${ }^{\mathrm{T}}$ supported novel natural bioactive compounds discovery by finding BGCs displaying unknown and low similarity with known BGCs. Further studies are needed using other test media, solidifying agents, incubation times and temperatures, and tested bacterial and fungal strains. It is carried out to improve and induce the production of bioactive compounds from these novel actinobacterial strains. Genome mining of four closely related novel candidate strains is recommended to confirm their identity, analyze their genome features, assess their secondary metabolite BGCs compared with the type strain, and predict their putative bioactive compounds.

\section{ACKNOWLEDGEMENTS}

This work was funded by the Institute of Fermentation (IFO; Osaka, Japan) to S. Y. and F. N., and Hibah Kompetitif Publikasi Internasional Terindeks Tugas Akhir Mahasiswa Doktor (TADok) Universitas Indonesia 2019 Research Grant (contract no. NKB0149/UN2.R3.1/HKP.05.00/2019) to W. S. We thank Prof. Paul Stothard, Ph.D. and Stothard Research Group from University of Alberta (Edmonton, Canada) for providing high-resolution versions of the genome map.

\section{REFERENCES}

Adamek M, Alanjary M, Sales-Ortells H, Goodfellow M, Bull AT, Winkler A, Wibberg D, Kalinowski J, Ziemert N. 2018. Comparative genomics reveals phylogenetic distribution patterns of secondary metabolites in Amycolatopsis species. BMC Genomics 19: 426. DOI: 10.1186/s12864-018-4809-4

Aigle B, Lautru S, Spiteller D, Dickschat JS, Challis GL, Leblond P, Pernodet J-L. 2014. Genome mining of Streptomyces ambofaciens. J Ind Microbiol Biotechnol 41: 251-263. DOI: 10.1007/s10295-0131379-y

Awakawa T, Fujita N, Hayakawa M, Ohnishi Y, Horinouchi S. 2011. Characterization of the biosynthesis gene cluster for alkyl-Odihydrogeranyl-methoxyhydroquinones in Actinoplanes missouriensis. Chembiochem 12 (3): 439-448. DOI: 10.1002/cbic. 201000628

Balouiri M, Sadiki M, Ibnsouda SK. 2016. Methods for in vitro evaluating antimicrobial activity: A review. J Pharm Anal 6 (2): 71-79. DOI: 10.1016/j.jpha.2015.11.005

Baltz RH. 2008. Renaissance in antibacterial discovery from actinomycetes. Curr Opin Pharmacol 8: 557-563. DOI: 10.1016/j.coph.2008.04.008 
Baltz RH. 2017. Gifted microbes for genome mining and natural product discovery. J Ind Microbiol Biotechnol 44: 573-588. DOI 10.1007/s10295-016-1815-x

Bankevich A, Nurk S, Antipov D, Gurevich AA, Dvorkin M, Kulikov AS, Lesin VM, Nikolenko SI, Pham S, Prjibelski AD, Pyshkin AV, Sirotkin AV, Vyahhi N, Tesler G, Alekseyev MA, Pevzner PA. 2012. SPAdes: a new genome assembly algorithm and its applications to single-cell sequencing. J Comput Biol 19 (5): 455-477. DOI: 10.1089/cmb.2012.0021

Barka EA, Vatsa P, Sanchez L, Gaveau-Vaillant N, Jacquard C, Klenk HP, Clement C, Ouhdouch Y, van Wezel GP. 2016. Taxonomy, physiology, and natural products of Actinobacteria. Microbiol Mol Biol Rev 80 (1): 1-43. DOI: 10.1128/MMBR.00019-15

Bassi CA, Benson DR. 2007. Growth characteristics of the slow-growing actinobacterium Frankia sp. strain CcI3 on solid media. Physiol Plant 130 (3): 391-399. DOI: 10.1111/j.1399-3054.2007.00866.x

Bentley SD, Chater KF, Cerdeño-Tárraga AM, Challis GL, Thomson NR, et al. 2002. Complete genome sequence of the model actinomycete Streptomyces coelicolor A3(2). Nature 417 (6885): 141-147. DOI: $10.1038 / 417141 \mathrm{a}$

Bérdy, J. 2012. Thoughts and facts about antibiotics: Where we are now and where we are heading. J Antibiot 65: 385-395. DOI: 10.1038/ja.2012.27

Blin K, Wolf T, Chevrette MG, Lu X, Schwalen CJ, et al. 2017. antiSMASH 4.0-Improvements in chemistry prediction and gene cluster boundary identification. Nucleic Acids Res 45: W36-W41. DOI: $10.1093 / \mathrm{nar} / \mathrm{gkx} 319$

Bode HB, Bethe B, Hofs R, Zeeck A. 2002. Big effects from small changes: possible ways to explore nature's chemical diversity. Chembiochemistry 3: 619-627. DOI: 10.1002/14397633(20020703)3: 7<619: AID-CBIC619>3.0.CO;2-9

Chen LY, Lai YM, Yang YL, Zhao XQ. 2016. Genome mining reveals the biosynthetic potential of the marine derived strain Streptomyces marokkonensis M10. Synth Syst Biotechnol 1: 56-65. DOI: 10.1016/j.synbio.2016.02.005

Dai H-Q, Wang J, Xin Y-H, Pei G, Tang S-K, Ren B, Ward A, Ruan J-S, Li W-J, Zhang L-X. 2010. Verrucosispora sediminis sp. nov., a cyclodipeptide-producing actinomycete from deep-sea sediment. Int $J$ Syst Evol Microbiol 60 (8): 1807-1812. DOI: 10.1099/ijs.0.017053-0

Das N, Tripathi N, Basu S, Bose C, Maitra S, Khurana S. 2015. Progress in the development of gelling agents for improved culturability of microorganisms. Front Microbiol 6: 698. DOI: $10.3389 /$ fmicb. 2015.00698

Donadio S, Monciardinia P, Sosio M. 2007. Polyketide synthases and non-ribosomal peptide synthetases: the emerging view from bacterial genomics. Nat Prod Rep 24: 1073-1109. DOI: 10.1039/B514050C

El-Naggar N, El-Ewasy S. 2017. Bioproduction, characterization, anticancer and antioxidant activities of extracellular melanin pigment produced by newly isolated microbial cell factories Streptomyces glaucescens NEAE-H. Sci Rep 7: 42129. DOI: 10.1038/srep42129

Eustáquio A, Ziemert N. 2018. Identification of natural product biosynthetic gene clusters from bacterial genomic data. Methods Pharmacol Toxicol: 1-21. DOI: 10.1007/7653_2018_32

Fischbach MA, Walsh CT. 2006. Assembly-line enzymology for polyketide and non-ribosomal peptide antibiotics: Logic, machinery, and mechanisms. Chem Rev 106 (8): 3468-3496. DOI: $10.1021 / \mathrm{cr} 0503097$

Funabashi M, Nonaka K, Yada C, Hosobuchi M, Masuda N, Shibata T, van Lanen SG. 2009. Identification of the biosynthetic gene cluster of A-500359s in Streptomyces griseus SANK60196. J Antibiot (Tokyo) 62 (6): 325-332. DOI: 10.1038/ja.2009.38

Gao G, Liu X, Xu M, Wang Y, Zhang F, et al. 2017. Formation of an angular aromatic polyketide from a linear anthrene precursor via oxidative rearrangement. Cell Chem Biol 24 (7): 881-891.e4. DOI: 10.1016/jchembiol.2017.06.008

Genilloud O. 2017. Actinomycetes: still a source of novel antibiotics. Natural Product Reports 34 (10): 1203-1232. DOI: 10.1039/c7np00026j

Gonzalez-Burgos E, Gomez-Serranillos MP. 2012. Terpene compounds in nature: A review of their potential antioxidant activity. Curr Med Chem 19 (3): 5319-5341. DOI: 10.2174/092986712803833335

Grant JR, Stothard P. 2008. The CGView Server: a comparative genomics tool for circular genomes. Nucleic Acids Res 36: W181-W184. DOI: 10.1093/nar/gkn179
Hamedi J, Wink J. 2017. Introduction. In: Wink J, Mohammadipanah F, Hamedi J (eds.). Biology and Biotechnology of Actinobacteria. Springer International Publishing AG, Switzerland.

Hamedi J, Poorinmohammad N, Wink J. 2017. The Role of Actinobacteria in Biotechnology. In: Wink J, Mohammadipanah F, Hamedi J (eds.). Biology and Biotechnology of Actinobacteria. Springer International Publishing AG, Switzerland.

Hatsu M, Sasaki T, Gomi S, Kodama Y, Sezaki M, Inouye S, Kondo S. 1992. A new tetracycline antibiotic with antitumor activity. I. Taxonomy and fermentation of the producing strain, isolation and characterization of SF2575. J Antibiot (Tokyo) 45 (3): 320-324. DOI: 10.7164/antibiotics.45.320

Hopwood DA. 1967. Genetic analysis and genome structure in Streptomyces coelicolor. Bacteriol Rev 31 (4): 373-403.

Hopwood DA, Sermonti, G. 1963. The genetics of Streptomyces coelicolor. Adv Genet 11: 273-342. DOI: 10.1016/s00652660(08)60289-8

Hu Y, Phelan V, Ntai I, Farnet CM, Zazopoulos E, Bachmann BO. 2007. Benzodiazepine biosynthesis in Streptomyces refuineus. Chem Biol 14: 691-701. DOI: 10.1016/j.chembiol.2007.05.009

Huang H, Yao Y, He Z, Yang T, Ma J, Tian X, Li Y, Huang C, Chen X, Li W, Zhang S, Zhang C, Ju J. 2011. Antimalarial $\beta$-carboline and indolactam alkaloids from Marinactinospora thermotolerans, a deep sea isolate. J Nat Prod 74: 2122-2127. DOI: 10.1021/np200399t

Igarashi Y, Trujillo M, Martínez-Molina E, Yanase S, Miyanaga S, Obata T, Sakurai H, Saiki I, Fujita T, Furumai T. 2007. Antitumor anthraquinones from an endophytic actinomycete Micromonospora lupini sp. nov. Bioorg Med Che. Lett 17: 3702-3705. DOI: 10.1016/j.bmcl.2007.04.039

Iorio M, Cruz J, Simone M, Bernasconi A, Brunati C, Sosio M, Donadio S, Maffioli SI. 2017. Antibacterial paramagnetic quinones from Actinoallomurus. J Nat Prod 80 (4): 819-827. DOI: 10.1021/acsjnatprod.6b00654

Ivanova V, Laatsch H, Kolarova M, Aleksieva K. 2013. Structure elucidation of a new natural diketopiperazine from a Microbispora aerata strain isolated from Livingston Island, Antarctica. Nat Prod Lett 27: 164-170. DOI: 10.1080/14786419.2012.665911

Kersten RD, Lane AL, Nett M, Richter TKS, Duggan BM, Dorrestein PC, Moore BS. 2013. Bioactivity-guided genome mining reveals the lomaiviticin biosynthetic gene cluster in Salinispora tropica. Chembiochem 14 (8): 955-962. DOI: 10.1002/cbic.201300147.

Kieser T, Bibb MJ, Buttner MJ, Chater KF, Hopwood DA. 2000. Practical Streptomyces genetics. The John Innes Foundation, Norwich, UK.

Kurtböke DI. 2012. Biodiscovery from rare actinomycetes: an ecotaxonomical perspective. Appl Microbiol Biotechnol 93 (5): 18431852. DOI: 10.1007/s00253-012-3898-2.

Lackner G, Schenk A, Xu Z, Reinhardt K, Yunt ZS, Piel J, Hertweck C. 2007. Biosynthesis of pentangular polyphenols: deductions from the benastatin and griseorhodin pathways. J Am Chem Soc 129 (30): 9306-9312. DOI: $10.1021 /$ ja0718624.

Li A, Piel J. 2002. A gene cluster from a marine Streptomyces encoding the biosynthesis of the aromatic spiroketal polyketide griseorhodin A. Chem Biol 9 (9): 1017-1026. DOI: 10.1016/s1074-5521(02)00223-5.

Li L, Wang P, Tang Y. 2014. C-glycosylation of anhydrotetracycline scaffold with SsfS6 from the SF2575 biosynthetic pathway. J Antibiot (Tokyo) 67 (1): 65-70. DOI: 10.1038/ja.2013.88

Liu Y, Li M, Mu H, Song S, Zhang Y, Chen K, He X, Wang H, Dai Y, Lu F, Yan Z, Zhang H. 2017. Identification and characterization of the ficellomycin biosynthesis gene cluster from Streptomyces ficellus. Appl Microbiol Biotechnol 101 (20): 7589-7602. DOI: 10.1007/s00253-017-8465-4.

Liu WT, Lamsa A, Wong WR, Boudreau PD, Kersten R, Peng Y, Moree WJ, Duggan BM, Moore BS, Gerwick WH, Linington RG, Pogliano K, Dorrestein PC. 2014. MS/MS-based networking and peptidogenomics guided genome mining revealed the stenothricin gene cluster in Streptomyces roseosporus. J Antibiot (Tokyo) 67 (1): 99-104. DOI: 10.1038/ja.2013.99.

Lopez P, Hornung A, Welzel K, Unsin C, Wohlleben W, Weber T, Pelzer S. 2010. Isolation of the lysolipin gene cluster of Streptomyces tendae Tü 4042. Gene 461 (1-2): 5-14. DOI: 10.1016/jgene.2010.03.016.

Matsuda K, Hasebe F, Shiwa Y, Kanesaki Y, Tomita T, Yoshikawa H, Shin-ya K, Kuzuyama T, Nishiyama M. 2017. Genome mining of amino group carrier protein-mediated machinery: Discovery and biosynthetic characterization of a natural product with unique hydrazone unit. ACS Chem Biol 12 (1): 124-131. DOI: 10.1021/acschembio.6b00818 
Mohammadipanah F, Dehhaghi M. 2017. Classification and taxonomy of Actinobacteria. In Wink J, Mohammadipanah F, Hamedi J (eds.) Biology and Biotechnology of Actinobacteria. Springer International Publishing AG, Switzerland: 51-77.

Ningsih F, Yokota A, Sakai Y, Nanatani K, Yabe S, Oetari A, Sjamsuridzal W. 2019. Gandjariella thermophila gen. nov., sp. nov., a new member of the family Pseudonocardiaceae, isolated from forest soil in a geothermal area. Int J Syst Evol Microbiol 69 (10): 3080-3086. DOI: 10.1099/ijsem.0.003594.

Niu G. 2018. Genomics-driven natural product discovery in actinomycetes. Trends Biotechnol 36 (3): 238-241. DOI: 10.1016/j.tibtech.2017.10.009.

Ōmura S, Ikeda H, Ishikawa J, Hanamoto A, Takahashi C, et al. 2001 Genome sequence of an industrial microorganism Streptomyces avermitilis: Deducing the ability of producing secondary metabolites. Proc Natl Acad Sci USA 98 (21): 12215-12220. DOI: 10.1073/pnas.211433198.

Onaka H, Nakaho M, Hayashi K, Igarashi Y, Furumai T. 2005. Cloning and characterization of the goadsporin biosynthetic gene cluster from Streptomyces sp. TP-A0584. Microbiology (Reading) 151 (Pt 12): 3923-3933. DOI: 10.1099/mic.0.28420-0.

Pan R, Bai X, Chen J, Zhang H, Wang H. 2019. Exploring structural diversity of microbe secondary metabolites using OSMAC strategy: A literature review. Front Microbiol 10: 294. DOI 10.3389/fmicb.2019.00294

Pickens LB, Kim W, Wang P, Zhou H, Watanabe K, Gomi S, Tang Y. 2009. Biochemical analysis of the biosynthetic pathway of an anticancer tetracycline SF2575. J Am Chem Soc 131 (48): 1767717689. DOI: $10.1021 /$ ja907852c.

Pickens LB, Sawaya MR, Rasool H, Pashkov I, Yeates TO, Tang Y. 2011 Structural and biochemical characterization of the salicylylacyltransferase SsfX3 from a tetracycline biosynthetic pathway. J Biol Chem 286 (48): 41539-41551. DOI: 10.1074/jbc.M111.299859.

Prabhu J, Schauwecker F, Grammel N, Keller U, Bernhard M. 2004 Functional expression of the ectoine hydroxylase gene (thpD) from Streptomyces chrysomallus in Halomonas elongata. Appl Environ Microbiol 70 (5): 3130-3132. DOI: 10.1128/aem.70.5.31303132.2004

Rabe P, Citron CA, Dickschat JS. 2013, Volatile terpenes from actinomycetes: A biosynthetic study correlating chemical analyses to genome data. Chem Biol Chem 14: 2345-2354. DOI: 10.1002/cbic. 201300329 .

Redenbach M, Kieser HM, Denapaite D, Eichner A, Cullum J, Kinashi H, Hopwood DA. 1996. A set of ordered cosmids and a detailed genetic and physical map for the $8 \mathrm{Mb}$ Streptomyces coelicolor A3(2) chromosome. Mol Microbiol 21 (1): 77-96. DOI: 10.1046/j.13652958.1996.6191336x.

Rutledge PJ, Challis GL. 2015. Discovery of microbial natural products by activation of silent biosynthetic gene clusters. Nat Rev Microbiol 13: 509-523. DOI: 10.1038/nrmicro3496.

Sari DCAF, Ningsih F, Yokota A, Yabe S, Sjamsuridzal W, Oetari A. 2020. IOP Conf Ser: Earth Environ Sci 483: 012017. DOI: 10.1088/1755-1315/483/1/012017.

Shirling ET, Gottlieb D. 1966. Methods for characterization of Streptomyces species. Intl J Syst Bacteriol 16 (3): 313-340.
Solecka J, Zajko J, Postek M, Rajnisz A. 2012. Biologically active secondary metabolites from actinomycetes. Cent Eur J Biol 7 (3): 373-390. DOI: 10.2478/s11535-012-0036-1.

Strobel T, Al-Dilaimi A, Blom J. Gessner A, Kalinowski J, Luzhetska M, Pühler A, Szczepanowski R, Bechthold A, Rückert C. 2012. Complete genome sequence of Saccharothrix espanaensis DSM $44229^{\mathrm{T}}$ and comparison to the other completely sequenced Pseudonocardiaceae. BMC Genomics 13: 465. DOI: 10.1186/14712164-13-465

Sun L, Wang S, Zhang S, Shao L, Zhang Q, Skidmore C, Chang C-WT, $\mathrm{Yu}$ D, Zhan J. 2016. Characterization of three tailoring enzymes in dutomycin biosynthesis and generation of a potent antibacterial analogue. ACS Chem Biol 11 (7): 1992-2001. DOI: 10.1021/acschembio.6b00245.

Suzuki S. 2001. Establishment and use of gellan gum media for selective isolation and distribution survey of specific rare actinomycetes. Actinomycetologica 15 (2): 55-60. DOI: 10.3209/saj.15_55.

Tanizawa Y, Fujisawa T, Nakamura Y. 2018. DFAST: a flexible prokaryotic genome annotation pipeline for faster genome publication. Bioinformatics 34: 1037-1039. DOI: 10.1093/bioinformatics/btx713.

Tian X-P, Long L-J, Li S-M, Zhang J, Xu Y, He J, Li J, Wang F-Z, Li WJ, Zhang C-S, Zhang S. 2013. Pseudonocardia antitumoralis sp. nov., a deoxynyboquinone-producing actinomycete isolated from a deepsea sediment. Int J Syst Evol Microbiol 63: 893-899. DOI: 10.1099/ijs.0.037135-0.

Tiwari K, Gupta RK. 2012. Rare actinomycetes: a potential storehouse for novel antibiotics. Crit Rev Biotechnol 32 (2): 108-132. DOI: 10.3109/07388551.2011.562482.

Yabe S, Aiba Y, Sakai Y, Hazaka M, Yokota A. 2010. Thermosporothrix hazakensis gen. nov., sp. nov., isolated from compost, description of Thermosporotrichaceae fam. nov. within the class Ktedonobacteria Cavaletti et al. 2007 and emended description of the class Ktedonobacteria. Int J Syst Evol Microbiol 60: 1794-1801. DOI: 10.1099/ijs.0.018069-0.

Yokota A, Ningsih F, Nurlaili DG, Sakai Y, Yabe S, Oetari A, Santoso I, Sjamsuridzal W. 2016. Paenibacillus cisolokensis sp. nov., isolated from litter of a geyser. Int J Syst Evol Microbiol 66: 3088-3094. DOI: 10.1099/ijsem.0.001151.

Yunt Z, Reinhardt K, Li A, Engeser M, Dahse H-M, Gütschow M, Bruhn T, Bringmann G, Piel J. 2009. Cleavage of four carbon-carbon bonds during biosynthesis of the griseorhodin a spiroketal pharmacophore. J Am Chem Soc 131 (6): 2297-2305. DOI: 10.1021/ja807827k.

Zhang X, Parry RJ. 2007. Cloning and characterization of the pyrrolomycin biosynthetic gene clusters from Actinosporangium vitaminophilum ATCC 31673 and Streptomyces sp. strain UC 11065. Antimicrob Agents Chemother 51 (3): 946-957. DOI: 10.1128/AAC.01214-06.

Zhang Q, Doroghazi JR, Zhao X, Walker MC, van der Donk WA. 2015. Expanded natural product diversity revealed by analysis of lanthipeptide-like gene clusters in Actinobacteria. Appl Environ Microbiol 81 (13): 4339-4350. DOI: 10.1128/AEM.00635-15.

Zheng Y, Saitou A, Wang C-M, Toyoda A, Minakuchi Y, Sekiguchi Y, Ueda K, Takano H, Sakai Y, Abe K, Yokota A, Yabe S. 2019. Genome Features and Secondary Metabolites Biosynthetic Potential of the Class Ktedonobacteria. Front Microbiol 10: 893. DOI: 10.3389/fmicb.2019.00893 